\title{
LII. On the behaviour of carbonic acid in relation to pressure, volume, and temperature
}

\section{Prof. R. Clausius}

To cite this article: Prof. R. Clausius (1880) LII. On the behaviour of carbonic acid in relation to pressure, volume, and temperature, Philosophical Magazine Series 5, 9:58, 393-408, DOI: $10.1080 / 14786448008626862$

To link to this article: http://dx.doi.org/10.1080/14786448008626862

册 Published online: 28 Apr 2009.

Submit your article to this journal $[\pi$

Џ Article views: 7

Q View related articles $₫$ 
LONDON, EDINBURGH, AND DUBLIN

\title{
PHILOSOPHICAL MAGAZINE
}

\author{
AND \\ JOURNAL OF SCIENCE.
}

[FIFTH SERIES.]

$J U N E 1880$.

LII. On the Behaviour of Carbonic Acid in relation to Pressure, Volume, and Temperature. By Prof. R. Clausius*.

T $\mathrm{N}$ relation to pressure, volume, and temperature, gases 1 follow, as is well known, with a certain degree of approximation, the laws of Mariotte and Gay-Lussac, which can in common be expressed by the following equation-

$$
p v=\mathrm{RT}, \text {. . . . . . . }
$$

wherein $p$ represents the pressure, $v$ the volume, and $\mathrm{T}$ the absolute temperature, while $R$ is a constant dependent on the nature of the gas. The further the gas in question is removed from its condensation-point the closer is the approximation to these laws. With those gases which under ordinary circumstances are so far from their condensation-point that, until recently, their condensation could not be effected, and which were therefore named permanent gases, the approximation is so close that for a long time it was believed that they followed these laws exactly, until Regnault, in his distinguished investigationst, first demonstrated some slight deviations. Somewhat later, Natterer $\ddagger$ showed that on the application of very powerful pressure very considerable deviations from Mariotte's law are obtained; and the deviations observed by him were

* Translated from a separate impression, communicated by the Author, from Wiedemann's Annalen, 1880, vol. ix. pp. 337-357.

† Reguault, Mém. de l'Acad.des Sciences, xxi. 1847.

I Natterer, Wiener Ber. v. (1850) p. 351, vi. (1851) p. 557, and xii. (1854) p. 199.

Phil. Mag. S. 5. Vol. 9. No. 58. June 1880. 


\section{Prof. R. Clausius on the Behaviour of Carbonic Acid}

of a different kind from those found by Regnault. That is to say, while Regnault had found that, with all the gases examined by him, the pressure increases more slowly than the density, in Natterer's experiments it turned out that with very great pressure the case is reversed, and the pressure increases more quick'y than the density: with air, nitrogen, and carbonic oxide gas the pressure already reached an amount of about 3000 atmospheres when the density had only become from 700 to 800 times that which exists under the pressure of one atmosphere.

Upon the causes on which these deviations of the gases from Mariotte's and Gay-Lussac's law depend, in my treatise "Ueber die Art der Bewegung, welche wir Wärme nennen"*, I expressed myself as follows:-

"In order that the law of Mariotte and Gay-Lussac, and the laws in connexion with it, may strictly hold good, the gas must, as regards its molecular state, satisfy the following conditions :-

"(1) The space actually filled by the molecules of the gas must be vanishingly little in comparison with the entire space taken up by the gas.

"(2) The time of a collision (i.e. the time required by a molecule, when it strikes against another molecule or a solid obstacle, in order to alter its motion in the manner in which it is altered by the collision) must, in comparison with the time which elapses between two collisions, be vanishingly short.

"(3) The influence of the molecular forces must be vanishingly little. This implies two things. In the first place, it is required that the force with which all the molecules at their mean distances attract each other vanish in comparison with the expansive force arising from the motion. But the molecules are not always at their mean distances from one another ; often in the course of the motion one molecule comes into the immediate vicinity of another or of a solid obstacle likewise consisting of operative molecules; and at such moments the molecular forces of course come into action. Hence the second requirement is that those parts of the path described by a molecule on which the molecular forces have an influence, perceptibly altering the motion of the molecule in direction and velocity, vanish when compared with the portions of the path on which the forces can be regarded as inoperative.

"If these conditions are not fulfilled, deviations in various directions from the simple law of the gases take place, which

* Clausius, Pogg. Ann. c. p. 358 (1857); and Abhandlungensammlung, ii. p. 235 . 
become so much the more considerable as the molecular state of the gas corresponds less to these conditions."

The deviations here mentioned must make themselves manifest, so far as the pressure is considered at a given temperature and a given volume, in this being either greater or less than it should be, according to Mariotte and Gay-Lussac's law, taking as the starting-point the highly rarefied state of the gas. The space above-mentioned (under 1) actually filled by the molecules conditions an augmentation of the pressure, since by it, at a given volume of the gas, the free space for the motion of the molecules is lessened, and accordingly the number of the collisions is increased. The molecular forces mentioned under 3 effect, when attraction prevails, a diminution of the pressure. The circumstance mentioned under 2 , namely the time that passes during a collision, has a more complicated effect, since, when two molecules rush against one another, first an acceleration, and only after this the retardation and reversal of the motion take place; hence, in considering the total effect, that of this circumstance can be joined partly to that of the first, partly to that of the last circumstance.

Of the two opposite effects of augmentation and diminution of pressure, the one or the other may preponderate, according to circumstances. The above-mentioned experiments of Regnault and Natterer show in hydrogen a universal preponderance of the increase of pressure, while they make known that in the other gases diminution of pressure predominates when the densities are less, and increase of pressure when the densities are greater.

The behaviour of a substance becomes still more complicated when on condensation it does not still remain gaseous, but changes its aggregate-state by becoming liquid. On the connexion of this process with those previously discussed some very fine experiments have recently been made by Andrews*. Submitting carbonic acid at various temperatures to powerful compressions, and observing the increases of pressure that took place, he found that there is an essential difference in its behaviour, according as the temperature is above or below $31^{\circ}$. Above $31^{\circ}$, only the above-mentioned deviations from Mariotte and Gay-Lussac's law are shown, while below $31^{\circ}$ at a certain pressure condensation takes place.

Andrews represents the relations between pressure and volume observed by him by curves which have pressure and volume as abscissæ and ordinates. The curves referring to temperatures above $31^{\circ}$ exhibit a continuous course; while those referring to temperatures below $31^{\circ}$ are broken, as with diminishing volume the pressure at first increases, but from a

* Andrews, Phil. Trans. 1869, p. 575.

$2 \mathrm{~F} 2$ 


\section{Prof. R. Clausius on the Behaviour of Carbonic Acid}

certain volume onwards, at which condensation begins, subsequent diminution of volume takes place without increase of pressure, and only when the volume has become much smaller and the entire mass is liquid, does the pressure again commence to increase as the volume is diminished, the increase then being rapid. The portion of the curve corresponding to the occurrence of condensation is a straight line, met at both ends by the continuously curved portions of the curve. A slight curvature delineated by Andrews at one extremity of the straight line appears to depend on a slight mixture of air, and hence may here be left out of consideration.

Two years afterwards James Thomson*, whose ingenious speculations have already so much contributed to the enlargement of mechanical and physical science, supplemented Andrews's curves by adding, at the places where in them a straight line is found, a curved line which joins on to the two curved portions of the curve given by Andrews in a continuous manner and represents a gradual transition from the gaseous to the liquid state, in which the entire quantity of the substance is found continuously in a similar state-a kind of transition which is theoretically thinkable, but cannot actually occur, because it contains intermediate states in which no stable, but only unstable, equilibrium exists. In fig. 1

Fig. 1.

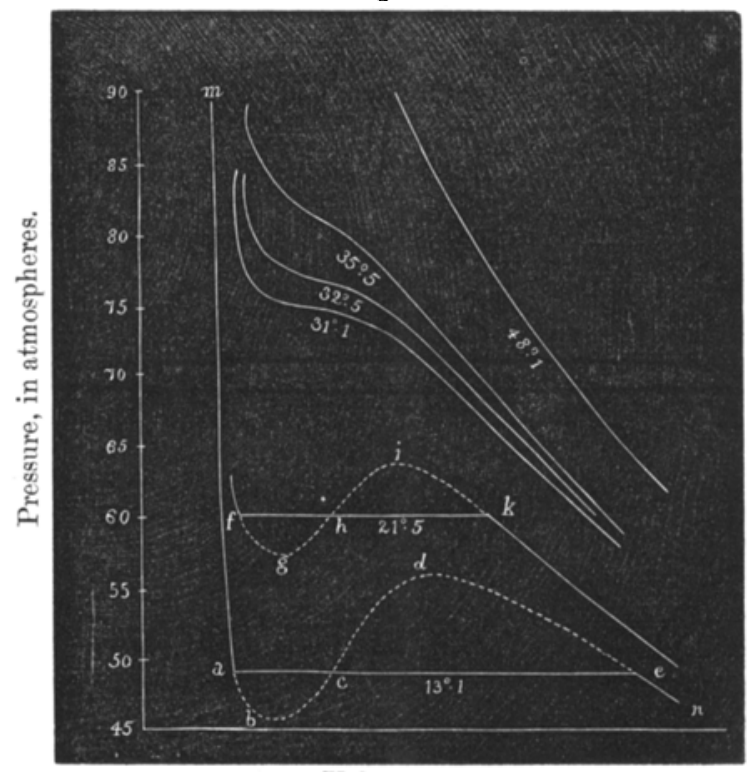

Volume.

* Proc. Roy. Soc. November 1871. 
Andrews's figure is reproduced with 'Thomson's supplementary curves added, drawn in dotted lines; only the external arrangement of the figure is altered, in a way first brought into use by Maxwell. Namely, Andrews represented in his figure the pressures by the abscissæ, and the volumes by the ordinates; but it is now customary, in the mechanical theory of heat, to represent the volumes by the abscissæ and the pressures by the ordinates, and the figure is redrawn in accordance therewith.

In the curves belonging to the temperatures $13^{\circ} \cdot 1$ and $21^{\circ} .5, a e$ and $f k$ are the above-mentioned straight lines corresponding to the occurrence of condensation, which J. Thomson has replaced by the dotted curved lines $a b c d e$ and fghik.

J. Thomson drew his conclusion respecting the form of these lines merely from the form of Andrews's curves belonging to the higher temperatures-tracing how these latter gradually change as they approach toward the temperature $31^{\circ}$, and then continuing the same kind of change below $31^{\circ}$. Upon an investigation of the reasons for this peculiar conformation of the pressure-curves, and the formation of a mathematical expression corresponding to them, he did not enter.

As regards the latter point (the mathematical treatment of the subject), attempts have been made by various authors, some before and some since Andrews's experimental investigation, to express the deviations of the gases from Mariotte and Gay-Lussac's law by an equation.

Rankine* constructed an equation in place of (1), with which also an equation derived by Sir W. Thomson and Joule $\dagger$ from their experiments on the changes of temperature that take place during the expansion of gases very closely agrees, and which in its simplest form can be written thus,

$$
p v=\mathrm{RT}-\frac{e}{\mathrm{~T} v}, \quad \cdot \quad \cdot \quad \cdot \quad \cdot \quad .
$$

in which $c$, as well as $\mathrm{R}$, denotes a constant.

Hirn $\ddagger$ effected upon equation (1) a transformation, in which the two above-mentioned circumstances that preeminently occasion deviation by gases from the law of Mariotte and Gay-Lussac, namely the volume of the molecules and their reciprocal attraction, are taken into account by the introduction of special quantities. The equation formed by him, which he says is applicable not merely to gases, but also to

* Phil. Trans. 1854, p. 336.

$\dagger$ Ibid. 1862, p. 579.

$\ddagger$ Théorie mécanique de la Chaleur, $2^{\mathrm{e}}$ éd. i. p. $195 ; 3^{\mathrm{e} e ́ d . ~ i i . ~ p . ~} 211$. 


\section{Prof. R. Clausius on the Behaviour of Carbonic Acid}

bodies in other states of aggregation, is

$$
(p+r)(v-\psi)=\mathrm{RT} . \quad \cdot \quad \cdot \quad \cdot
$$

Herein $\psi$ denotes "la somme de volumes des atomes," and $r$ "la somme des actions internes ;" the latter quantity he also names "la pression interne." In his further treatment of this equation, by which he seeks to determine the quantities $\psi$ and $r$, he makes inferences which seem to me not to be justified, and the result of which therefore, in my opinion, does not correspond with the reality.

Recknagel, in a memoir* which appeared in 1871, and which he supplemented in 1872, formed instead of (1) an equation agreeing externally with that set up by Rankine. It has the form

$$
p v=\mathrm{RT}\left(1-\frac{\mathrm{B}_{t}}{v}\right), \quad \cdot \quad \cdot \quad \cdot .
$$

in which $\mathrm{R}$ is a constant, and $\mathrm{B}_{t}$ a function of the temperature, which latter Recknagel determines differently from Rankine, since according to him it is directly proportional to the absolute temperature, and inversely proportional to the corresponding pressure of the saturated vapour of the given substance.

J. D. van der Waals, in a very interesting work $\dagger$ published since Andrews's above-cited experiments, has substituted for (1) an equation in which, as in Hirn's, the two circumstances, the space filled by the molecules and the reciprocal attraction of the molecules, are taken into account: it has the form

$$
\left(p+\frac{a}{v^{2}}\right)(v-b)=\mathrm{RT}, . . . .
$$

or, resolved with respect to $p$,

$$
p=\mathrm{R} \frac{\mathrm{T}}{v-b}-\frac{a}{v^{2}}, \quad . \quad \cdot \quad \cdot \quad \cdot .
$$

where $\mathrm{R}, a$, and $b$ are constants. The values of these constants for carbonic acid Van der Waals determined $\ddagger$ as follows, taking as unit of pressure one atmosphere, and as unit of volume that which the carbonic acid occupies under the pressure of one atmosphere at the freezing-point; the quantity $\mathrm{T}_{0}$ standing as denominator in the value of the first constant represents the absolute temperature corresponding to the freezing-point, consequently approximately the number $273:-$

* Pogg. Ann. Ergbd. v. p. 563, \& cxlv. p. 469.

$\dagger$ Over de Continuiteit van den Gas- en Vloeistoftoestand (Leiden, 1873), p. 56 .

$\ddagger$ Op. cit. p. 76 . 


$$
\left.\begin{array}{rl}
\mathrm{R} & =\frac{1.00646}{\mathrm{~T}_{0}}, \\
a & =0.00874, \\
b & =0.0023 .
\end{array}\right\} \cdot \cdot \cdot \cdot \cdot \cdot \cdot
$$

This equation, extraordinarily simple in form, gives pressurecurves corresponding well with those constructed by Andrews and supplemented by $\mathrm{J}$. Thomson, and exhibiting likewise the characteristic difference between the forms which belong to temperatures above and below $31^{\circ}$.

As to the more precise numerical accordance of the values of $p$ calculated from this equation with those observed by Andrews, Van der Waals himself made the remark that with volumes less than 0.0046 the value of $p$ can no longer be regarded as constant, but must become less as the volume decreases. But by what function of the volume one has to represent $b$ he had not yet succeeded in discovering*.

In addition to these there are other deviations, which could only reveal themselves later; for after the publication of Van der Waals's work the stock of observations suitable for comparison with the calculated values received a great and important enrichment, as Andrews continued his investigation, and published in 1876 three new series of observations for the temperatures $6^{\circ} .5,64^{\circ}$, and $100^{\circ} \dagger$, which far surpass those previously published in extent and possess an enhanced degree of exactness. On comparison with these experiments, the equation set up by Van der Waals is found not to agree with experience, and cannot be brought into accordance even by altering the values attributed to the constants, but needs for that purpose a more essential modification.

The principal reason of these deviations appears to me to be the following. Van der Waals assumed it as self-evident that the mutual attraction of the molecules is independent of the temperature, and therefore can only be a function of the volume. According to that, when a gas is heated at constant volume the molecular attraction must remain unaltered. This would doubtless be true if the motion of the molecules of a gas at a lower temperature differed from that at a higher temperature only by the different quantity of the mean vis viva of the motion, but in all other respects took place in precisely the same manner, the paths of all the molecules and the ratios of the velocities in the different stages of a path remaining the same. I also believe that such an assumption respecting the

* Op. cit. pp. 78 \& 52.

† Phil. Trans. 1876, p. 421. 
homogeneity of the motion would be admissible in considering only the ideal state, which we call the perfect state of a gas; but when we have to investigate the deviations of a gas from the perfect state, that assumption appears to me to be inadmissible.

I will not here advance any definite theory about the way in which the motion changes when a gas leaves the perfect state ; but I will take leave to adduce a mode of alteration as at least a possible one. For the perfect gaseous state it may be assumed that every two molecules that rush together separate again after the collision. On the contrary, when the gas is condensed to liquidity, a quite different behaviour takes place: namely, the molecules are in general held together by their mutual attraction; and only exceptionally, on a specially favourable coincidence of the phases of motion, do individual molecules separate themselves from the rest of the mass. Now, between these two extreme cases one can well imagine an intermediate state of this kind:-As a rule, indeed, the molecules separate again after the collision; but it sometimes happens that two molecules after meeting do not again separate, but only oscillate about one another while carrying out the progressive motion in common, until, by the change that takes place in the motion on further collision, the separation is again occasioned. The number of such pairs of attached molecules would then become so much the greater the lower the temporature (and hence the less the mean vis viva of the motion) became; and on a further fall of the temperature there might supervene instances of not merely two, but several molecules holding together and executing as groups the progressive motion in common.

If such a behaviour occurred, the mean strength of the mutual attraction of the molecules would be thereby increased, since the molecules remaining united would of course, on account of the greater nearness, attract one another more strongly; and, accordingly, it would not be allowable to regard the quantity which represents in the formula the mutual attraction of the molecules as independent of the temperature, but one would be obliged to admit that it becomes greater with falling temperature.

Van der Waals has, further, from theoretical considerations, drawn the conclusion, also already expressed by others in their formulæ, that the decrease of pressure conditioned by the mutual attraction of the molecules is inversely proportional to the square of the volume. It may be granted that for larger volumes this conclusion is approximately correct; and yet no universal and rigorous validity need be ascribed to it, but one 
may assume that from it also a deviation takes place which becomes the greater the smaller the volume becomes.

Now I have tried to construct for $p$ a formula which retains what appears to me to be correct in previous formulæ, but at the same time makes allowance for the above-mentioned modifying circumstances, and, while as simple as possible, is in satisfactory accordance with both the older and the newer observations of Andrews, as well as with the other extant observations. This, on account of a peculiar circumstance, is beset with great difficulties. The formula to be formed for $p$ has, as may be seen even from the equations (2), (3), (4), and (5) when solved with respect to $p$, the peculiarity that it is the difference of two quantities which may both have much higher values than $p$. The effect of this is, that inaccuracies which in proportion to the two single quantities are but little may yet in $p$ produce deviations from experiment considerable in comparison with its value, and therefore each single quantity must be so much the more precisely determined.

The formula which I have constructed has the following form :-

$$
p=\mathrm{R} \frac{\mathrm{T}}{v-\alpha}-\frac{c}{\mathrm{~T}(v+\beta)^{2}}, \quad . \quad . \quad . \quad .
$$

wherein $\mathrm{R}, c, \alpha$, and $\beta$ are constants.

For carbonic acid these constants, if (as before) the chosen unit of pressure be one atmosphere, and the unit volume that which is occupied by the carbonic acid under the pressure of one atmosphere and at the temperature of the freezing-point, are to have the following values:-

$$
\left.\begin{array}{rl}
\mathrm{R} & =\frac{1.00682}{\mathrm{~T}_{0}}=0.003688, \\
c & =2.0935, \\
\alpha & =0.000843, \\
\beta & =0.000977 .
\end{array}\right\} . . .
$$

If, on the other hand, as pressure-unit the pressure of a kilogram upon a square metre, and as volume-unit a cubic metre be chosen, it being presupposed that the quantity of carbonic acid is a kilogram, we have to attribute to the constants the following values:-

$$
\left.\begin{array}{l}
\mathrm{R}=19 \cdot 273, \\
c=5533, \\
\alpha=0.000426, \\
\beta=0.000494 .
\end{array}\right\} \cdot . \cdot \cdot . \cdot
$$




\section{Prof. R. Clausius on the Behaniour of Carbonic Acid}

In order to test the accordance of this formula with experiment, I selected for comparison the three newer series of observations made by Andrews which relate to the temperatures $6^{\circ} .5$, $64^{\circ}$, and $100^{\circ}$, and three of the older series, referring to the temperatures $13^{\circ} \cdot 1,31^{\circ} \cdot 1$, and $48^{\circ} \cdot 1$. In each of these series, I selected for consideration, out of the volumes therein occurring, a number which are distributed as equally as possible over the entire interval of observation. I have, however, to remark that Andrews has not so expressed the volumes that all the numbers have one and the same unit for a base, but with each temperature he has taken as unit that volume which the carbonic acid, under the pressure of one atmosphere, occupies at that temperature. The volume thus expressed he designates by $\epsilon$. In order to calculate from this the volume we designate by $v$ (which has for its fundamental unit the volume occupied by the carbonic acid at the freezing-point under the pressure of one atmosphere), we must know the coefficient of expansion of carbonic acid under atmospheric pressure. For this the value found by Regnault, $0 \cdot 00371$, and which Andrews used in his calculations, is employed.

The values thus obtained of $v$ are, together with the respective temperatures, inserted in the formula, and then from these the values of $p$ belonging to them calculated. These values are designated in the following Tables by " $p$ (calc.);" and below them are the corresponding observed values, designated by " $p$ (obs.)." $\Delta$ denotes the differences between the observed and the calculated values of $p$. At each series it is stated whether it belongs to the older or the newer series of Andrews's observations.

TABLe 1.-Temp. $6^{\circ} 5$ (newer series).

\begin{tabular}{|c|c|c|c|}
\hline$\epsilon$. & $\frac{1}{16 \cdot 1 \overline{3}}$ & $\frac{1}{29 \cdot 62}$ & $\frac{1}{45 \cdot 80}$. \\
\hline 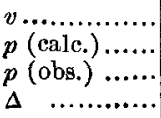 & $\begin{array}{c}0.06349 \\
14.65 \\
\mathbf{1 4 . 6 8} \\
-\quad 0.03\end{array}$ & $\begin{array}{c}0.03458 \\
24 \cdot 63 \\
24.81 \\
-0.18\end{array}$ & $\begin{array}{c}0.02236 \\
34 \cdot 15 \\
34.49 \\
-\quad 0.34\end{array}$ \\
\hline
\end{tabular}

TABLE II.-Temp. $13^{\circ} \cdot 1$ (older series).

\begin{tabular}{|c|c|c|c|c|}
\hline e. & $\frac{1}{76 \cdot 16}$ & $\frac{1}{80 \cdot 43^{\circ}}$ & $\frac{1}{480 \cdot 4}$ & $\frac{1}{510 \cdot 7}$ \\
\hline $\begin{array}{c}v \ldots \ldots \ldots \\
p(\text { calc. }) \\
p \text { (obs. }) \\
\Delta \ldots \ldots \ldots \ldots\end{array}$ & $\begin{array}{c}0.013768 \\
47.98 \\
47.50 \\
+\quad 0.48\end{array}$ & $\begin{array}{c}0.013037 \\
49.27 \\
48.76 \\
+\quad 0.51\end{array}$ & $\begin{array}{c}0.0021828 \\
54.66 \\
54.56 \\
+\quad 0.10\end{array}$ & $\begin{array}{c}0.0020532 \\
74.96 \\
90 \cdot 43 \\
-15.47\end{array}$ \\
\hline
\end{tabular}


TABle III.-Temp. $31^{\circ} \cdot 1$ (older series).

\begin{tabular}{|c|c|c|c|c|c|}
\hline E. & $\frac{1}{80 \cdot 55}$ & $\frac{1}{124 \cdot t}$ & $\frac{1}{174.4}$ & $\frac{1}{311 \cdot 1}$ & $\frac{1}{405 \cdot 5}$ \\
\hline $\begin{array}{l}v \ldots \ldots \ldots \\
p(\text { calc. }) \ldots \\
p(\text { obs. }) \ldots \\
\Delta \ldots \ldots \ldots \ldots\end{array}$ & $\begin{array}{c}0.0138+7 \\
54.92 \\
54.79 \\
+\quad 0.13\end{array}$ & $\begin{array}{c}0.008966 \\
68.41 \\
67.60 \\
+\quad 0.84\end{array}$ & $\begin{array}{c}0.006395 \\
75.33 \\
7383 \\
+\quad 1.50\end{array}$ & $\begin{array}{c}0003585 \\
78.22 \\
75.40 \\
+\quad 282\end{array}$ & $\begin{array}{c}0.002751 \\
92 \cdot 47 \\
83 \cdot 19 \\
+\quad 7.28\end{array}$ \\
\hline
\end{tabular}

Table IV.-Temp. $48^{\circ} \cdot 1$ (older series).

\begin{tabular}{|c|c|c|c|}
\hline 6. & $\frac{1}{86-45}$ & $\frac{1}{1468}$ & $\frac{1}{298 \cdot 4}$ \\
\hline $\begin{array}{l}v \\
p(\text { calc. }) \\
p \text { (cbs. }) \ldots \ldots \\
\Delta \\
\Delta \quad \ldots \ldots \ldots \ldots\end{array}$ & $\begin{array}{c}0.013631 \\
62 \cdot 05 \\
62.60 \\
-\quad 0.55\end{array}$ & $\begin{array}{c}0 \cdot 008028 \\
84.42 \\
8435 \\
+\quad 007\end{array}$ & $\begin{array}{c}0.003949 \\
112.6 \\
109.4 \\
+\quad 32\end{array}$ \\
\hline
\end{tabular}

TABLE V.-Temp. $64^{\circ}$ (newer series).

\begin{tabular}{|c|c|c|c|c|c|}
\hline E. & $\frac{1}{24 \cdot 18}$ & $\frac{1}{46 \cdot 34}$ & $\frac{1}{83 \cdot 44}$ & $\frac{1}{185.5}$ & $\frac{1}{446^{2} \cdot 4}$ \\
\hline $\begin{array}{l}v \\
p(\text { calc. }) \ldots \\
p(\text { obs. }) \ldots \\
\Delta \quad \ldots \ldots \ldots\end{array}$ & $\begin{array}{c}0 \cdot 05118 \\
22 \cdot 41 \\
22.56 \\
-\quad 0.15\end{array}$ & $\begin{array}{c}0.02670 \\
39.95 \\
40.54 \\
-\quad 0.59\end{array}$ & $\begin{array}{c}0.01483 \\
63.99 \\
64.96 \\
-\quad 0.97\end{array}$ & $\begin{array}{c}0.006671 \\
107.06 \\
106.88 \\
+\quad 0.18\end{array}$ & $\begin{array}{r}0 \cdot 002772 \\
202 \cdot 30 \\
2 \cdot 2 \cdot 92 \\
-\quad 20 \cdot 62\end{array}$ \\
\hline
\end{tabular}

TABLE VI.-Temp. $100^{\circ}$ (newer series).

\begin{tabular}{|c|c|c|c|c|c|}
\hline$\epsilon$. & $\frac{1}{26 \cdot 09}$ & $\frac{1}{50 \cdot 63}$. & $\frac{1}{46 \cdot 65}$ & $\frac{1}{2180}$ & $\frac{1}{379 \cdot 3}$ \\
\hline $\begin{array}{l}v \ldots \ldots \ldots \\
p(\text { calc. }) \ldots \\
p(\text { obs. }) \ldots \\
\Delta \ldots \ldots \ldots \ldots\end{array}$ & $\begin{array}{c}0.05255 \\
24 \cdot 65 \\
24 \cdot 85 \\
-\quad 0.20\end{array}$ & $\begin{array}{c}0.02708 \\
45.30 \\
45.99 \\
-0.69\end{array}$ & $\begin{array}{c}0.014185 \\
78.69 \\
80.25 \\
-\quad 1.56\end{array}$ & $\begin{array}{c}0.006289 \\
146.29 \\
145.44 \\
+\quad 0.85\end{array}$ & $\begin{array}{r}0.003615 \\
230.09 \\
223.57 \\
+\quad 6.52\end{array}$ \\
\hline
\end{tabular}

From these Tables it is evident that there is in general a satisfactory, and in part a strikingly good accordance between the values of $p$ calculated from the formula and those observed; nevertheless, at the greatest densities of carbonic acid reached in the experiments, amounting to four or five hundred times the densities occurring under the pressure of one atmosphere, considerable differences are met with. These at first induced me to undertake another modification of the formula, by introducing into the second term a temperature-function as a factor in order to balance the differences. Through this, however, the formula lost its simplicity; and the question arose whether 


\section{Prof. R. Clausius on the Behaviour of Carbonic Acid}

these differences were really of so much importance as to justify such an alteration of the formula. This question, upon closer consideration of the matter, 1 believed must be answered in the negative.

For the differences change their signs in quite a striking manner : at $13^{\circ} \cdot 1$ the greatest difference is negative, at $31^{\circ} .1$ positive, at $64^{\circ}$ negative, and at $100^{\circ}$ again positive. So frequent a change of sign does not make for the supposition that the cause of the differences lies in the formula, but rather that it is to be sought in errors of observation; and in the case in question such errors are very well conceivable, even with the most careful observation. The volume of the highly condensed carbonic acid was measured in capillary tubes. Now, when it had become so small as to amount to only one four- or five-hundredth part of its original magnitude, errors might easily occur in the reading, which, though absolutely very small, were relatively great enough to cause, in the formula for $p$, of which the value very rapidly changes with $v$ when the values of $v$ are small, differences from the quantities in the Table.

Besides, the air-manometer used for the determination of the pressure consisted of a capillary tube, in which the air, when the greatest pressures occurred, occupied volumes so small that a slight error of observation must have exerted a very great influence upon the pressure deduced from the observation.

Further, it is to be remarked that Andrews, in deducing the pressure from the data supplied by the air-manometer, started from the hypothesis that air follows Mariotte's law up to the greatest pressures employed in the experiments, which reached more than 200 atmospheres. But this, it is well known, is not the case; at such pressures considerable deviations take place. I at first tried to take advantage of the observations of Cailletet and Amagat on the compression of nitrogen, in order to correct the pressure-quantities deduced from the manometer-indications; but I found that the results of their observations are not sufficiently accordant with each other to be employed with safety for such a correction. Hence I have simply quoted in the Tables Andrews's values of $p$.

Lastly, I must call attention to a peculiar distinction which appears in the differences between the observed and the calculated values of $p$ : namely, in the older series the differences are almost all positive, and in the newer almost all negative. This also makes for the hypothesis that the differences originate rather in the circumstances affecting the experiments than in the formula. 
For all these reasons it must be concluded that some uncertainty still attaches to the highest observed values of $p$; and consequently accordance between the calculated and the observed values must not be too strictly insisted on. I therefore abandoned the above-mentioned complicating alteration of the formula, and reverted to its original and most simple form, which seems to me, not only in respect of practice, but of theory also, to deserve preference.

By rather laborious calculations I so determined the constants of the formula that the resulting values of $p$ agreed as well as possible with both the newer and the older results of observation obtained by Andrews, and that, of the differences remaining at high densities of the carbonic acid, about as many are positive as negative. With these values of the constants there is also a satisfactory accordance with Regnault's results of observation, which in regard to the condensation of carbonic acid do not extend so far, by a long way, as those of Andrews. I therefore think that these values of the constants correspond with sufficient accuracy to the stock of observations at present existing, which is more complete as regards carbonic acid than with respect to any other gas.

To the other gases the general equation (7) can, in my opinion, be applied; but of course the constants must be determined for each gas.

In connexion with the foregoing another question must be discussed, which forces itself upon us in the consideration of the curves drawn by Andrews and completed by James Thomson.

When a gas, e. g. carbonic acid, is compressed at a temperature below the critical temperature, at a certain volume condensation begins; and therewith a state enters in which one portion of the substance is liquid and the other gaseous. As long as this state continues, with the further diminution of the volume the pressure remains constant, and the corresponding part of the isothermal pressure-curve is consequently a horizontal straight line. Beside this straight line, one can imagine, as was discussed above, according to James Thomson, another isothermal pressure-curve, representing that pressure which would take place at the same change of volume if this proceeded in such wise that constantly the entire quantity of the substance was in the same state. Although this latter kind of change of volume does not really take place, because the states of equilibrium occurring in it are in part unstable, yet it must be regarded as theoretically possible ; and, in fact, the latter pressure-curve represents the pressure determined by our formula. 


\section{Prof. R. Clausius on the Behaviour of Carbonic Acid}

But now comes the question, In what position do this theoretical pressure-curve and the horizontal straight line corresponding to the actual process stand to each other?

James Thomson has expressed no opinion upon it, but has only, in Andrews's figure (reproduced in fig. 1), added to the pressurve-curves referring to the temperatures $13^{\circ} .1$ and $21^{\circ .5}$ the curve-portions there drawn in dotted lines. These were probably only intended to give a rough idea of the possible form and position of the portions of the curves. In that form they cannot be accepted as really correct.

Maxwell, in the first edition of his ' Theory of Heat,' p. 125, goes into the matter more closely. If one of the theoretical continuous pressure-curves, e. g. that belonging to the temperature $13^{\circ} \cdot 1$, be imagined to be given, and if the horizontal straight line be drawn at different heights, two points $a$ and $e$ are always obtained as the extreme points of the straight line. The difference between the two values possessed by the energy of the substance in the states corresponding to those two points differs in magnitude for the different positions of the straight line. Now, says Maxwell, that position of the straight line at which this difference is a maximum is the correct one. In the fourth edition, however, the passage is altersd and the position of the straight line left undetermined. It must therefore be assumed that Maxwell afterwards relinquished his previous view on this point.

Van der Waals says (in p. 121 loc. cit.), "I have not succeeded in finding in any of the properties of saturated vapour a characteristic by which it could be determined where the [straight] line must be drawn through the isotherms."

After this the question what position the horizontal straight line giving the pressure of saturated vapour has in the isothermal pressure-curve may well be regarded as still an open one; and I wish to be permitted to communicate here the answer to this question which has presented itself to me on consideration of the subject.

When the pressure-curve drawn by Andrews and completed by James Thomson for the temperature of $13^{\circ} \cdot 1$, is examined, it is seen to be single from $m$ to $a$ and again from $e$ to $n$, while it is double between $a$ and $e$. Between the two states of the substance corresponding to the points $a$ and $e$ (and which we will briefly name states $a$ and $e$ ) there are consequently two ways in which the substance can pass out of the one into the other. The transition can take place on both of these paths, under perfectly similar circumstances, in the direction from $a$ to $e$ and also in the direction from $e$ to $a$; the respective changes are therefore both to be designated as reversible. 
Now, if we imagine the substance making the transition from $a$ to $e$ along the path represented by the curve $a b c d e$, and returning from $e$ to $a$ along the path represented by the straight line $e a$, we have a reversible cyclical process. Hence, for the positive or negative quantity of heat communicated from without to the changing substance in the course of this process, an element of which may be called $d \mathrm{Q}$, the well-known equation

$$
\int \frac{d \mathrm{Q}}{\mathrm{T}}=0
$$

must hold good. And since in the present case the temperature $\mathrm{T}$ is constant, and the lines which graphically represent the cyclical process are only isothermal lines for one and the same temperature, the equation simplifies itself into

$$
\int d Q=0 \text {. }
$$

Therefore the positive and negative quantities of heat communicated to the substance eliminate one another.

It hence follows, further, that the positive and negative parts of the external work done during the cyclical process must also counterbalance one another. The excesses of the positive work over the negative belonging to the two sections of the cyclical process are represented by the areas occurring in the figure: the area $c d e c$ above the straight line represents a positive, and the area $a b c a$ beneath the same line a negative excess. Consequently these two areas must, in order to give 0 for the value of the total work, be equal the one to the other. Hereby, when the theoretical pressure-curve corresponding to the homogeneous state is given, the position of the horizontal straight line answering to the actual processes of vaporization and condensation is also determined.

The foregoing condition can be expressed as a proposition thus:-The pressure of the saturated vapour is so great that the external work performed at the vaporization is equal to that which would be performed if, the increase of volume being the same, the substance remained homogeneous. This can also be put still more briefly thus:-The pressure of the saturated vapour is equal to the mean pressure of the substance remaining homogeneous while receiving an inerease of volume corresponding to complete vaporization.

The curve drawn between $a$ and $e$ by $J$. Thomson for the temperature $13^{\circ} \cdot 1$ does not correspond to this condition; for the areas of the figures $a b c a$ and $c d e c$ formed by it and the horizontal straight line are visibly unequal. Now, in order to see what is the form taken when equation (7) is employed 
408 Prof. R. Clausius on the Behaviour of Carbonic Acid.

for the determination of the pressure, I have calculated the corresponding values of $p$ for so many values of $v$ lying between $a$ and $e$ that from them may be understood the course of the curre between $a$ and $e$. The values therein obtained, together with the values of $p$ already given above in Table II. referring to some values of $v$ outside of the interval $a e$, are collected in the following Table :-

\begin{tabular}{|c|c|c|c|c|c|c|c|c|c|}
\hline $\begin{array}{l}v \\
p\end{array}$ & …... & $\begin{array}{c}0.013768 \\
47.98\end{array}$ & $\begin{array}{c}0 \cdot 013037 \\
49 \cdot 27\end{array}$ & $\begin{array}{l}0 \cdot 012 \\
51 \cdot 12\end{array}$ & $\begin{array}{l}0 \cdot 011 \\
52 \cdot 87\end{array}$ & $\begin{array}{l}0 \cdot 010 \\
54 \cdot 50\end{array}$ & \multicolumn{2}{|c|}{$\begin{array}{l}0.009 \\
55 \cdot 84\end{array}$} & $\begin{array}{l}0.008 \\
56.63\end{array}$ \\
\hline$v$ & $\begin{array}{l}\ldots . . . \\
\cdots \ldots . . \\
\cdots\end{array}$ & $\begin{array}{l}0.007 \\
56.38\end{array}$ & $\begin{array}{l}0 \cdot 006 \\
54 \cdot 28\end{array}$ & $\begin{array}{l}0.005 \\
49.00\end{array}$ & $\begin{array}{l}0.004 \\
38.83\end{array}$ & $\begin{array}{c}0.00350 \\
32 \cdot 05\end{array}$ & \multicolumn{2}{|c|}{$\begin{array}{c}0.00325 \\
28.83\end{array}$} & $\begin{array}{c}0.00300 \\
26.53\end{array}$ \\
\hline$v$ & & \multicolumn{2}{|c|}{$\begin{array}{c}0 \cdot 00285 \\
26 \cdot 11\end{array}$} & $\begin{array}{c}0.00275 \\
26.52\end{array}$ & $\begin{array}{c}0.00250 \\
31.52\end{array}$ & \multicolumn{2}{|c|}{$\begin{array}{c}0.0021828 \\
54 \cdot 66\end{array}$} & \multicolumn{2}{|c|}{$\begin{array}{c}0.0020532 \\
74.96\end{array}$} \\
\hline
\end{tabular}

On the employment of these values a curve is obtained of the form given in fig. 2. This curve corresponds with satisfactory accuracy to the above condition.

Fig. 2.

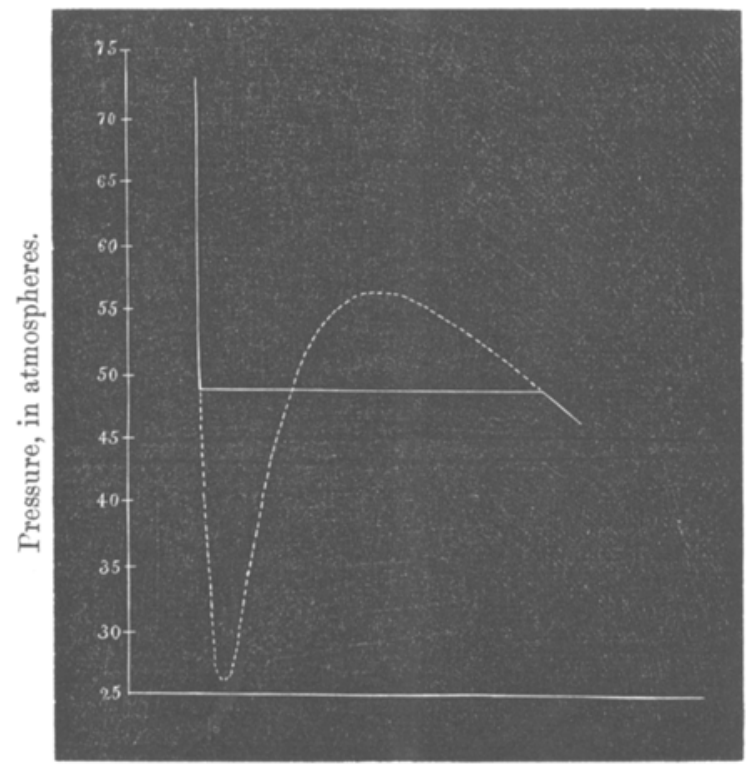

Volume. 